\title{
Long-term care reform in Germany - at long last
}

\author{
S. $\operatorname{Link}^{*}$ \\ Presented to the Institute \& Faculty of Actuaries, 17 September 2018, Staple Inn, London \\ *Correspondence to: Sabrina Link, General Reinsurance AG, Theodor-Heuss-Ring 11, 50668 Cologne, Germany. \\ Email: Sabrina.elena.link@genre.com
}

\begin{abstract}
Demographic and societal changes make it more and more indispensable to protect against the risk of care costs surpassing a person's financial means. Nevertheless, only few governments have acted to create public funding systems that, if existent at all, usually only cover part of the expenses for elder care. Long-term care insurance (LTCI) is designed to fund basic care needs in later life, such as washing and dressing. Regardless of where individuals receive this support in old age, how it is funded is a growing issue. In many countries, people may augment their compulsory state system with private policies available from insurance companies.

In Germany, a well-established public system that underwent major reforms exists. From 2017 onwards, a completely new care definition and assessment process replaced the former ones. Two major changes constitute the reform: First, when evaluating the need for care, the former focus on estimating the length of time required for care was replaced by the determination of the degree of independence. Second, cognitive impairments will be acknowledged more adequately than in the past, where the focus was on physical abilities. Furthermore, the contribution to be paid by the care recipient in a nursing home will no longer be dependent on the severity of the care need.

In Germany, private LTC products used a combination of the social security definition, an ADL-based trigger and a dementia trigger until the end of 2016. Thus, the reform has repercussions for the local private insurance industry. What would happen to in-force business, how a new benefit trigger should look like, how old and new definition compare and how pricing rates can be derived were only some of the questions that had to be answered in advance.

The reform could point the way for future public schemes and private policies elsewhere. Which questions had to be answered and what issues had to be solved in advance, together with lessons learned during and shortly after the reform was undertaken, can serve as an accompaniment for the introduction or reform of public LTC schemes and for the local insurance industry in other countries.
\end{abstract}

Keywords: Long-term care; Germany; Activities of daily living

\section{Introduction}

In many countries, how the support in old age is funded is a growing issue. At the start of 2017, the German compulsory long-term care insurance (LTCI) scheme underwent comprehensive reform that reframed the definition of care. Besides introducing a new "in need of care" definition, the reform also added a new evaluation instrument for determining the need for care.

This paper gives background information on the German LTC social security system, presents the new definition and the new care assessment and points out the major changes. It focuses on lessons learned and first experience under the new system which might be interesting and helpful for other countries. It concludes with the implications this reform has for the private insurance industry with respect to in-force policies, designing of new products and pricing. 


\section{Main text}

\subsection{Background}

LTCI, be it public or private, shall protect against costs that arise from care needs. It provides a cover against the risk of becoming too frail to care for oneself without the physical assistance from another person even when using assistive devices. Demographic and societal changes continue to put pressure on society with respect to elder care. In particular, increasing life expectancy and decreasing fertility rates mean that more people reach a care-relevant age with fewer people to support them. While life expectancy at age 65 was only 12.8 years for men and 16.3 years for women in Germany (12.6 for men and 16.6 for women in the United Kingdom) in 1980, it was already 17.9 years for men and 21.0 years for women (18.6 for men and 20.8 for women in the United Kingdom) in 2015 (OECD, 2019a). This signifies an increase of 4 to 6 years. In most developed countries, the fertility rate has been below the replacement rate of 2.1 for decades now. It was only 1.5 in Germany (1.8 in the United Kingdom) in 2015 and has been this low since the early 1970s (OECD, 2019b). An increased mobility of the younger generations, a higher labour participation by women and the fact that families are getting smaller and less stable imply that close relatives who have been the traditional choice are less likely to take on the role of caregivers.

In countries where a public system that encompasses elderly care exists, these demographic and societal changes exert pressure on the social system since they translate into a smaller share of the population that is of working age. A measure that puts a number on this phenomenon is the oldage dependency ratio. It sets the number of persons aged 65 and over (the age when they are generally economically inactive) in relation to the number of persons aged between 15 and 64 (working age). In the EU-28 countries, this ratio is projected to increase from 0.288 in 2015 to 0.503 in 2050, which indicates that only two persons of working age will be there to support one pensioner (Eurostat, 2019).

The majority of people will need care support during a certain period before death. The experience from a German public health insurer reveals that more than half of all men and almost three out of four women require care at the end of their lives and that more than $80 \%$ of them require it for more than 3 months (Rothgang et al., 2015). Finding solutions to fund the care of the elderly is therefore of key importance in ageing societies.

\subsection{Germany}

Germany is one of the few countries with an established public LTC system and where government and private solutions coexist. In 1995, the public LTC insurance scheme was introduced as the last of the five pillars of social insurance in Germany. Coverage is compulsory, and people are usually insured through their health insurer. The financing of the scheme is based on a pay-asyou-go system. The contribution rate has increased from $1 \%$ of gross income at the outset to now $2.55 \%$ and is shared equally between employee and employer. Those without children pay a surcharge of 0.25 percentage points. The principles of the system are first the partial nature of the scheme. It bears around half of the actual cost incurred by an individual in need of care. And second, home health care should take precedence over nursing home care. The benefits are not means-tested and vary, depending on whether a cash benefit or the reimbursement of care costs is chosen and whether care is provided at home or in a nursing home.

When the compulsory LTCI scheme was introduced, it had three care levels. The assessment of the level of care took account of the frequency and duration of the assistance required to provide for personal hygiene, feeding, mobility and housekeeping needs. Other activities, such as measures to promote the communication and the general care, were explicitly not taken into account. Reacting to the criticism of the focus on physical abilities a "level 0" was added later. Small levels of benefit were granted to individuals with limited daily living skills including mainly those with 
cognitive impairments such as dementia but no physical care needs. In addition, the highest care level differentiated so-called hardship cases that manifested extremely high and intensive care needs which surpassed the usual extent in care level III.

The three care levels and hardship cases were defined by the following criteria.

1. Persons in care level I require assistance for the basic activities personal hygiene, feeding and mobility at least once a day and in addition several times a week for housekeeping.

2. Persons in care level II require assistance for the basic activities at least three times a day and in addition several times a week for housekeeping.

3. Persons in care level III require assistance for the basic activities daily around the clock, also at night and in addition several times a week for housekeeping.

The length of time a non-professional spends on caring for the dependent person has to amount to

1. at least 90 minutes of which more than 45 minutes for the basic activities in care level I

2. at least 3 hours of which at least 2 hours for the basic activities in care level II

3. at least 5 hours of which at least 4 hours for the basic activities in care level III

weekly on average per day.

Persons in care level III count as hardship cases either if they need assistance for the basic activities for at least 6 hours daily of which at least three times at night or if the assistance for the basic activities can only be rendered by several care persons together, also at night. Hardship cases are present especially for terminal cancer, terminal AIDS, high paraplegia and tetraplegia, vigil coma and severe manifestation of dementia among others.

\subsection{The reform}

Two features of the care assessment and definition were criticised from outset: the insufficient consideration of cognitive aspects and the unsuitable counting of minutes as a criterion to assess the need for care. Over the course of the years, various legal extensions were therefore driven forth, but never included a thorough reform of the system. Benefits were expanded, "level 0" was introduced (first only for those with a care level, later for all) and a provident fund was established. Since 2013, a government initiative promoted private insurance by subsidising (small) premiums, the so-called Pflege-Bahr. Nevertheless, a reform was concretely envisaged already in 2006 when an advisory committee to review the care definition was initialised. This committee accomplished much important groundwork such as outlining a new definition and assessment after thorough research and pre-testing the proposed assessment instrument. Due to changing governments after elections and shifted priorities further work was delayed, but not abolished. A second committee revised and concretised the new care definition, and two larger studies were conducted to validate the new assessment process. Finally, in 2015 the "Second Pflegestärkungsgesetz (PSG II)" (second strengthening-of-care act) was passed and took effect at the beginning of 2017, thus more than 10 years after its initialisation. It is embedded within the framework of the "First Pflegestärkungsgesetz" which brought an expansion of benefits and the set-up of the LTC fund in early 2015 and the "Third Pflegestärkungsgesetz" which shall strengthen the care counselling in the municipalities from 2017 on. Increasing the contribution rate by 0.2 percentage points the financing of the PSG II was deemed sufficient at the time. Recently, the Ministry of Health announced another increase by at least 0.2 percentage points from 2019 onwards. 


\subsection{The New Care Assessment and Definition}

The new evaluation instrument for determining the need for care comprises six modules that are weighted differently in the final overall score:

1. Mobility (10\%)

2. Cognitive and communicative abilities (higher value from modules 2 and 3 , in total 15\%)

3. Behaviour and psychiatric problems (higher value from modules 2 and 3, in total 15\%)

4. Self-care $(40 \%)$

5. Dealing with requirements due to illness or therapy (20\%)

6. Organisation of everyday life and social contacts (15\%)

Each module consists of various items. For each item, the assessor records how independently the applicant can perform an activity, if or to what extent an ability is present or how often a certain behaviour occurs. The applicant receives one of the five care grades if the total score is above 12 points of a total of 100 points. For the highest care grade, a special rule applies. It is granted if the applicant has a score of at least 90 points or has lost the use of both arms and both legs.

The assessment philosophy is characterised by five fundamental changes:

1. The allotment of time required for care was replaced by the degree of independence. Heretofore, the evaluation was based on how often and how long the dependent person needed assistance. To that end, the assessor drew on benchmarks as reference points, a complete takeover of the activities by a lay caregiver being assumed. For example, a full-body wash was graded with 20 to 25 minutes. From now on, to what extent the applicant can shower or bath independently will be captured.

2. The former deficit orientation is replaced by a resource orientation. It is therefore not a question of what the person in need of care can no longer do, but rather what he or she is still able to do.

3. Previously, the need for care in some activities of daily living (ADL) was taken into account which consisted of personal hygiene, nutrition, mobility and household assistance. In the future, there will be a comprehensive consideration of the care need. Cognitive and psychiatric impairments will be considered especially in the modules 2 and 3 and to some extent in the modules 5 and 6 . In the modules 1 and 4 , on the other hand, special emphasis is placed on physical impairments which continue to be of great relevance due to the high weight of these modules in the total score.

4. The earlier three care levels have been replaced by five care grades. The lowest care grade only serves as a type of preliminary level, though, with an easy-to-achieve minimum score and relatively low-cost reimbursement benefits that can be used only for their specified purpose.

5. In the past, a person had to actually be dependent on assistance for the respective activity. In the future, it will be irrelevant whether the activity in question actually occurs. For example, the independence when climbing stairs will be assessed even if there are no stairs in the individual living environment of the applicant.

It is noteworthy that with regard to inpatient care, the contribution to be paid by the person will no longer be dependent on the care grade (except for the lowest care grade). A transition to a higher care grade will therefore not lead to higher contributions which used to lead to conflicting interests between the nursing home operators and the person in need of care or rather his or her relatives. The exact amount of the deductible and additional costs for investments, board and lodging differs from nursing home to nursing home, though. 
For those who already received benefits from the public LTCI system before the reform, the protection of the status quo is politically intended. They are automatically transferred into the new care grades and continue receiving at least the former benefits. A former categorisation into care level $x$ is transferred to care grade $x+1$. If the dependent person also has limited daily living skills, he or she is transferred to care grade $x+2$. For example, an individual with care level II before 2017 will be categorised into care grade 3 . If limited daily living skills were observed in addition to care level II, the person will be categorised into care grade 4 .

\subsection{Implications for Private Insurance}

Additional private LTCI policies are available from both the health and life insurance line sometimes with considerable differences. Health insurers offer daily allowances, subsidised LTCI policies and the less and less important cost reimbursement policies, while life insurers offer annuities. Due to the possibilities to adjust premiums in daily care allowances, the higher guarantee level (including a surrender value) in care annuities and varying interest rates, the price-performance ratios of the policies cannot be compared directly. The initial premium for daily care allowances may appear less expensive when looked at in isolation. This may be one of the most important reasons why the number of in-force policies for health insurers is much higher amounting to 3.6 million at the end of 2016 (PKV, 2016). Even though life insurers managed a portfolio of only 208,000 policies, they enjoyed a strong growth in recent years (GDV, 2018). Between 2005 and 2016 the number of policies increased by $26 \%$ on average per year compared to an average annual increase of $14 \%$ for health insurance products.

For the LTCI policies offered by health insurers, Germany's PSG II act provides for a special adjustment right for conditions and premiums, and provides even a duty to adjust the tariffs in compulsory private LTCI and nationally subsidised additional LTCI policies. Additional private policies follow the procedure in the compulsory private LTCI. For one, this means that the new definition of "in need of care" will be used in new business. It also means benefits offered under existing policies have been adapted based on the new definition of "in need of care".

Products available from the life insurance line previously used three definitions - the legal definition of "in need of care", a definition based on ADL and an independent definition of dementia - as benefit triggers. The legal definition was typically copied into the contract wording at a certain point in time with a commentary that changes in the public definition would not lead automatically to changes of the tariff, implying that claims management retained the right to do their own assessment. Because the need for financial support typically increases with the level of dependency tiered benefits were very popular. This means that the benefit amount depends on the care level or the number of failed ADLs. For example, the insured person receives a partial benefit when failing four out of six ADLs, fulfilling the requirements for care level II or when suffering from dementia and the full benefit in the highest category. In future claims assessments involving pre-existing policies, either these three benefit triggers will have to be taken into consideration which does not seem impossible since the assessment report based on the new evaluation guidelines will be available or the insured person will have opted to switch to a new policy - an option that most recent tariffs offer. No new underwriting is required, but the change of tariff must not lead to an extension of the cover which can lead to a changed (usually lower) benefit than before due to the more generous nature of the new care definition. Switching to a new tariff can have advantages for the policyholder even though some specifics such as the gender-differentiated calculation and higher guaranteed interest rates in earlier product generations have to be dealt with adequately. Legal experts contend that if the cover is not extended when switching to a new tariff the calculation does not have to change to unisex nor does the interest rate have to change to the current one. 
Due to the legal definition, one must ask how a new policy should look. Sticking to the old care levels would do the carrier no favour nor in the public image neither in claims management. On the other hand, life insurers have been engaged predominantly with other issues such as regulatory requirements or the reorientation of private pension products, with the result that only little capacity is available for revising the LTC product. Thus, there are currently providers that, for the time being, are continuing to use the old care levels or are not using the legal definition at all, favouring the definitions of ADLs and dementia instead.

It is worth considering whether to use the new legal definition exclusively, which covers both physical and psychological disabilities. A separate definition of dementia would then no longer be necessary. On the other hand, a parallel definition of ADLs could at least provide a fall-back option in case of future reforms of the public LTC system even though this might seem unlikely at the moment since the flaws of the old definition appear to have been corrected. Aside from that, such a parallelism would follow the former market standard. Both variants are currently to be found on the market: Some carriers have opted to use only the new social security definition going forward, while others combine it with an ADL definition complemented by a cognitive element to imitate the legal definition.

Tiered benefits still make sense for home health care since the need for financial support continues to be different for each care grade. For nursing home care, this is no longer the case due to the aforementioned new regulation that the contribution to be paid is no longer dependent on the care grade. However, no one will be able to tell whether potential care will be delivered at home or in a nursing home when taking out LTCI. Most products on the market offer an individual fixing of the benefit amount per care grade.

As mentioned earlier, the lowest care grade, care grade 1, serves as a type of preliminary level with an easy-to-achieve minimum score and relatively low mandatory benefits. The calculation of this care grade involves a number of uncertainties as the assumption regarding the number of additional benefit recipients to be expected has a major impact. It therefore seems wise to offer no cover or only very low cover for care grade 1, for example, in the form of a lump-sum benefit. Even starting a waiver of premiums when care is required at care grade 1 could become problematic if the premium income is lower than previously calculated. Therefore, for most products on the market, care annuities can only be paid, and premiums only waived, from care grade 2 upwards.

Differentiating between care grades 4 and 5 is fraught with higher uncertainties than when looking at the other care grades. Mostly cases with the former care level III can be expected in both care grades. Since further progressed cases with care level III were underrepresented in the studies prior to the reform, differentiating between these two care grades in the calculation is very risky. Furthermore, the average time needed to provide care is nearly the same in care grades 4 and 5. Thus, it is recommendable to allow for the same or at least very similar benefit amounts in these care grades. Some products on the market combine the highest two care grades at the outset. Products with fixed levels of benefits offer a high percentage of benefits in care grade 4 .

One must also consider whether the assessment of risks in medical underwriting has to change. Dementia-related or mental illnesses affecting behaviour and conditions that involve the patient in the monitoring and treatment processes are weighted more heavily than in the past. Fundamental changes in the previous assessments are unnecessary. For example, due to the predictability of care dependency it was normally impossible to obtain insurance for psychotic schizophrenia, especially when dementia represented an independent benefit trigger.

Another major question is how pricing rates can be derived for the new definition when there has been no actual experience at all. The former relatively robust rates for care levels can be transferred to the new definition using, for one thing, contingency tables of care levels and 
care grades. These can be obtained from the studies prior to the reform during which applicants were assessed simultaneously with regard to the former and the new assessment system. Various adjustments might be necessary like taking into account the effect of "lifting-over-the-threshold": When assessing claimants with real benefits resulting from it, a gap in the distribution of the scores at the threshold to the next higher care level can be observed. This means that almost no claimant receives a result close to the next higher care level, but clusters receive a score just over it. Scores close to the next higher care level would only lead to objections, and due to the worsening state of health in almost all care recipients a reassessment only a short time later would confirm the justification of the higher care level. In a study setting, however, this gap cannot be observed, but will probably occur for care grades as well. In addition, assumptions about the number of additional benefit recipients are necessary. These are the people who were not care dependent with regard to the old system, but will be granted a care grade in the new system. One approach is to estimate the number of those who applied but were rejected in the care level system and those who never claimed but are likely to do so in the care grade system. With the new system being in place for over a year now, first numbers have been published. Public sickness funds which account for ca. $94 \%$ of care recipients have stated that by the end of 2017 around 304,000 people were granted a care grade, but would not have received benefits in the old system (MDS, 2018).

\section{Conclusion}

The objective of providing more appropriate care grading through the LTC reform appears to have been achieved. In the future, people with cognitive and mental health problems will be shown the same recognition for their limitations as people with purely physical impediments. Resource orientation and a focus on the degree of independence replace deficit orientation and the focus on the length of time required for care.

The design of the new care definition and assessment may serve as an inspiration for public LTC schemes elsewhere, be it for schemes to be newly introduced or existing ones to be adjusted. Linking the benefit trigger of a private LTC product to the public definition entails a lot of questions that have to be solved in advance in case of a reform. The challenges for the private insurance industry pointed out earlier may help private insurers in other countries weigh whether to use the local definition in their products or to use an independent benefit trigger like one based on ADLs. The first has the advantage of a high recognition value for the potential policyholders, but the example of Germany shows that dealing with a reform is a complex and effortful task.

Even though many questions had to be clarified for the practical implementation, some German providers of private LTCI have already integrated the new definition of "in need of care" into their products. It remains to be seen how the private insurance market will develop in light of the reform. Insurers will have to maintain a balance between comprehensive insurance cover and payable premiums, as private LTCI will remain one of the fastest-growing and future-proof products on the German insurance market, not least due to the demographic trend.

Acknowledgements. The author would like to thank Tim Eppert for his helpful input in finalising this paper.

\section{References}

Eurostat, the statistical office of the European Union (2019). Projected old-age dependency ratio, https://ec.europa.eu/ eurostat/web/products-datasets/-/tps00200.

Gesamtverband der Deutschen Versicherungswirtschaft e.V. (GDV) (2018). Statistische Zeitreihen des Versicherungszweigs der Lebensversicherung im engeren Sinne, Struktur des Bestandes, Zeitreihen LV Bestand an Hauptversicherungen 1970 bis 2017, 06.04.2018. 
Medizinischer Dienst des Spitzenverbandes Bund der Krankenkassen e.V. (MDS) (2018). Pressemitteilung, Bilanz nach einem Jahr: neue Pflegebegutachtung hat Praxistest erfolgreich bestanden, Essen, 18. Januar 2018, https://www.mds-ev. de/uploads/media/downloads/18-01-18_-_PM_Ergebnisse_der_Pflegbegutachtung.pdf.

OECD (2019a). Life expectancy at 65 (indicator). doi: 10.1787/0e9a3f00-en (Accessed on 25 April 2019) https://data.oecd.org/ healthstat/life-expectancy-at-65.htm.

OECD (2019b). Fertility rates (indicator). doi: 10.1787/8272fb01-en (Accessed on 25 April 2019) https://data.oecd.org/pop/ fertility-rates.htm.

Rothgang, H., Kalwitzki, T., Müller, R., Runte, R. \& Unger, R. (2015). BARMER GEK Pflegereport 2015. Schriftenreihe zur Gesundheitsanalyse, Band 36. Siegburg: Asgard-Verlagsservice.

Verband der Privaten Krankenversicherung e.V. (PKV) (2016). Zahlenbericht der Privaten Krankenversicherung, https:// www.pkv.de/service/zahlen-und-fakten/archiv-pkv-zahlenbericht/zahlenbericht-2016.pdf.

Cite this article: Link S. (2019) Long-term care reform in Germany - at long last. British Actuarial Journal, 24. https://doi.org/ 10.1017/S1357321719000096 